\title{
SUPERDOTAÇÃO: UMA QUESTÃO HISTÓRICO-DISCURSIVA EM TRÊS TEMPOS
}

\section{GIFTEDNESS: A THREE-STAGE HISTORICAL-DISCURSIVE ISSUE}

\author{
Cássio Eduardo Miranda ${ }^{1}$ \\ Universidade Federal do Piauí, PI, Brasil
}

\begin{abstract}
Resumo: Este artigo discute a construção discursiva do conceito de superdotação com seus possíveis efeitos na atualidade. Localiza o discurso a respeito da inteligência como um ato discursivo e como, a partir da modernidade, a discursividade sobre a inteligência e a superdotação associa-se ao discurso do capital. A partir de discussões conduzidas por Michel Foucault (1967) e Jacques Lacan (1956; 1969), trata de como a atualidade se insere em uma lógica produtiva baseada em um discurso que valoriza e hiperestimula o alto desempenho.
\end{abstract}

Palavras-chave: Superdotação; Ato discursivo; Subjetividade.

Abstract: This article discusses the discursive construction of the concept of giftedness with its possible effects today. It locates the discourse on intelligence as a discursive act and how, from modernity, discourse on intelligence and giftedness is associated with the discourse of capital. Based on discussions conducted by Michel Foucault (1967) and Jacques Lacan $(1956 ; 1969)$, it deals with how the present day is inserted in a productive logic based on a discourse that values and hyper-stimulates high performance.

Keywords: Giftness; Discoursive act; Subjectivity

\section{INTRODUÇÃO}

Este artigo tem como finalidade discutir a construção discursiva da superdotação, tendo como referência três acontecimentos discursivo-temporais, a saber: a era clássica, a modernidade e o século XX. A partir das discussões de Michel Foucault e Jacques Lacan, busca localizar o discurso sobre a inteligência como um ato discursivo com seus efeitos decorrentes. Finalmente, problematiza os usos que o cência faz de tal noção inserindo-a na educação a partir de uma lógica do Capital.

A era globalizada, por sua complexidade, não suporta explicações mecanicistas e reducionistas. O mundo contemporâneo, confuso, com traços paradoxais, mostra, no entanto, um notável avanço no progresso das técnicas e das ciências, assim como um avanço no campo das diferenças sociais e até mesmo subjetivas. Se por um lado vive-se em uma torre de Babel, em que diversificadas línguas, idiomas, culturas e práticas pessoais convivem de modo quase

\footnotetext{
${ }^{1}$ Doutor em Educação pela Universidade Feral do Rio de Janeiro (UFRJ), professor do Programa de Pós-Graduação em Saúde e Comunidade e do Programa de Pós-graduação em Saúde da Família do Centro de Ciências da Saúde da Universidade Federal do Piauí. E-MAIL: cassioedu@ufpi.edu.br. ORCID: https://orcid.org/0000-0002-8990-1205.

Revista Tópicos Educacionais, Pernambuco, v. 27, n. 01, p. 154-173, 2021. ISSN: 2448-0215.

https://periodicos.ufpe.br/revistas/topicoseducacionais/index DOI: 10.51359/2448-0215.2021.250111
} 
incompreensível, por outro lado, o Pentecoste ${ }^{2}$ se realiza através do Pensamento Único ${ }^{3}$ sugerido pelos aparatos da mundialização. Para Santos (2000, p. 18), esse discurso mundializado é imposto às pessoas através de produções discursivas e fabulações e “[...] seus fundamentos são a informação e o seu império, que encontram alicerce na produção de imagens e do imaginário, e se põem ao serviço do império do dinheiro, fundado este na economização e na monetarização da vida social e da vida pessoal". Por essa via, verifica-se que o discurso midiático, ao mesmo tempo em que produz fabulações, narrativas, discursos formadores, norteia-se por uma lógica em que o capital funciona como "o sopro de vida" apto a movimentar o corpo da máquina midiática e social.

A partir disso, podemos dizer que nos encontramos hoje em uma "aldeia global", como têm alarmado estudiosos da mundialização (SANTOS, 2000). Com todos os avanços no campo das ciências tecno-informacionais e com a consolidação da globalização, os meios de comunicação tornaram o mundo mais próximo e promoveram uma contração do planeta, através da emanação de modos de convivência e de pensamento. É notório como as novas tecnologias significam modificações quantitativas e qualitativas para os processos comunicacionais. Sabe-se que as tecnologias de rede, os acessos cada vez mais popularizados da web, as notícias instantâneas e as veiculações por satélite facilitam a divulgação de signos universalizados, o que prefigura uma memória coletiva diferenciada da memória enraizada, localizada, partícipe de uma cultura regional.

Já faz algum tempo que teóricos das mais diversas áreas, como Anthony Giddens (2000), Zygmunt Bauman (1999), Jacques-Alain Miller (2006), Gilles Lipovetsky (2007) e Frederic Jameson (2006) têm discutido as alterações no tempo atual sem que necessariamente tais alterações representem uma mudança no modus vivendi da modernidade - como pressupõe o termo "pós-modernidade" - mas representam, conforme já dito, em uma exacerbação nos valores, nas estruturas e nos modos de aliança entre as personagens desta era. Tal exacerbação pode ser chamada também de Alta Modernidade, Hipermodernidade, Capitalismo Tardio ou Modernidade Líquida. A contemporaneidade, assim, não supõe uma ruptura com a modernidade, mas, mais que

\footnotetext{
${ }^{2}$ Refiro-me aqui à narrativa neotestamentária encontrada no livro de Atos dos Apóstolos, em que diversas pessoas de variadas línguas, culturas e nações encontravam-se em Jerusalém para a festa da colheita - a festa do Pentecoste - e os apóstolos pregaram, segundo a narrativa, movidos pelo Espírito Santo. De acordo com o texto, esses discípulos de Jesus Cristo pregavam em suas línguas nativas - o hebraico - e as pessoas entendiam cada uma em sua própria língua.

${ }^{3}$ Segundo Santos (2000), o Pensamento Único é o pensamento imposto sutilmente pela globalização, que tende a mundializar os discursos, tornando-os uma única maneira de se construir representações sobre a política, a economia e os modos de produção.
}

Revista Tópicos Educacionais, Pernambuco, v. 27, n. 01, p. 154-173, 2021. ISSN: 2448-0215.

https://periodicos.ufpe.br/revistas/topicoseducacionais/index 
isso, aparece como uma mudança baseada na exacerbação de algo que já existia. Tal como tem se constituído, pode-se dizer que se vive em um tempo em que mecanismos imagéticos midiáticos tornaram-se modeladores de certo modo de ser sujeito. Dentre os traços característicos desse momento, pode-se perceber uma dependência da imagem, a valorização do instantâneo e a busca de satisfação imediata e contínua como valores predominantes.

É oportuno recordar que a "aldeia global" encurtou as distâncias e promoveu o crescimento de técnicas de homogeneização dos fazeres e dos ideais. Com este conjunto de técnicas, defendemos que as mídias, paulatinamente, assumiram uma face invasora, que não se contenta em ficar em um único lugar, mas que busca ampliar seu território, seu campo de produção e, inclusive, criar gêneros midiáticos híbridos ${ }^{4}$, em função de uma hegemonia e de uma inteligência global. De um lado, se é o aspecto fundamental da informação que cria a sensação de uma redução do tempo e do espaço, de outro, as identidades psicossociais também são atingidas, pois o universo midiático cede à tirania do capital e à tirania da informação, mas, ao mesmo tempo, estabelece a hegemonia de um pensamento único subordinada a identidades que se tornam referenciais universais. Tal constatação faz-se necessária para tentar localizar o lugar da inteligência no discurso contemporâneo, sobretudo em sua construção discursivo-temporal.

\section{A educação dos bem-dotados: primórdios do conceito}

Embora o significante "superdotação" seja, de certo modo, produto da modernidade e resultado de um trabalho das ciências psicológicas e cognitivas, a história da educação permite-nos inferir que o interesse por indivíduos portadores de altas habilidades não é algo apenas deste tempo, mas também uma preocupação que vem de eras remotas. Conforme tentaremos demonstrar, o conceito "superdotado" assenta-se em um tipo de racionalidade ${ }^{5}$,

\footnotetext{
${ }^{4}$ Um gênero híbrido é aquele que apresenta diversos gêneros textuais ou discursivos presentes em um mesmo gênero. Trata-se de um fenômeno chamado de hibridização, em que há uma mescla de gêneros ou intertextualidade intergêneros. Consiste na possibilidade dos gêneros se apresentarem de forma híbrida, isto é, assumindo a forma de outro gênero. Assim, podemos verificar o gênero publicitário, a título de exemplo, em que há também a presença de elementos jornalísticos e científicos; ou as novelas, em que aspectos pedagógicos são nela inseridos. Para maiores informações, cf: Koch (2006).O hibridismo textual é um recurso muito utilizado por produtores de texto para chamar a atenção do leitor. No entanto, este leitor precisa ter um conhecimento prévio de gêneros textuais. Não um conhecimento formal, acadêmico, mas, um conhecimento de mundo que permita que o mesmo possa distinguir os objetivos colocados em cada texto que lê.
}

${ }^{5}$ A noção de racionalidade, termo proveniente da Teoria do Conhecimento, aplica-se à produção de saberes, de enunciados explicativos ou de teorias que são coerentes com as construções científicas, com os cânones ou o "espírito científico" de uma dada época. A racionalidade pode constituir, assim, em oposição à irracionalidade, um critério para Revista Tópicos Educacionais, Pernambuco, v. 27, n. 01, p. 154-173, 2021. ISSN: 2448-0215. https://periodicos.ufpe.br/revistas/topicoseducacionais/index DOI: 10.51359/2448-0215.2021.250111 
consequentemente, tem múltiplos efeitos. Trata-se, aqui, de verificar como se deu, historicamente, a constituição desse conceito e como ele foi validado através do uso de sucessivas regras de formação e uso, os elementos teóricos, filosóficos e sociais que possibilitaram sua elaboração e continuidade. Assim, a superdotação será tomada como "fato de discurso", ou seja, como elemento construído historicamente com base em dimensões psicossociais, linguísticas e imaginárias, daí nossa discussão, no início deste capítulo, em torno das produções midiáticas.

No classicismo grego já encontramos, em Platão, um programa de educação especial destinado àqueles que, em tese, possuíam algum potencial intelectual mais avançado. Para os gregos dessa época, a busca pela forma ideal, abstrata e perfeita era a regra que se aplicava aos mais diversos campos do saber humano. Com isso, temos uma combinação que só poderia resultar em uma busca pelos mais aptos ao governo da cidade: de um lado um programa de educação especial e, de outro, a busca pela forma ideal e perfeita. Para a Paideia - o processo educativo grego - pensada por Sócrates, a competência técnica deve vir associada a uma preocupação com o conteúdo moral de tal processo. Caso isso não ocorra, relata Giles (1987), a tragédia pessoal e a desintegração da sociedade são inevitáveis. Assim, a formação do aluno depende de uma virtude que pode ser ensinada pela reflexão e o estudo de valores sociais importantes para uma dada cultura e sociedade. A crença dos atenienses era a de que a Cidade-Estado tornar-se-ia mais forte à medida que cada menino desenvolvesse integralmente suas aptidões. E a educação possuía tal missão.

Conforme destaca Cohen (2006), na Antiguidade, os gregos estimavam sobremaneira a educação e a viam como um elevado conceito de valores a serem seguidos e perpetuados. Para eles, sustenta essa autora, a educação tem a função de transmitir aspectos relacionados tanto à vida individual quanto à vida social. Trata-se, assim, de um modo de vida que se constrói com base na força geradora dos ideais, algo que se perpetua, no que diz respeito à educação, até nossos dias.

Em A república (409 a. C [1972]), Platão considera que a criança portadora de alguma habilidade intelectual destacada deve ser treinada de uma forma diferente das demais. Isso porque, para ele, o processo educativo visa, antes de tudo, à formação de sujeitos que devem exercer a liderança na vida social. Em sua perspectiva, a escolha do candidato deverá basear-se, para cada

qualificar determinados saberes, crenças, mitos e ideologias das sociedades tradicionais e modernas. in Popper, K. (1966): Les Fondements Philosophiques des Systemes Economiques, Paris: Ed. Emil M. Classen, Payot, p. 148-150.

Revista Tópicos Educacionais, Pernambuco, v. 27, n. 01, p. 154-173, 2021. ISSN: 2448-0215.

https://periodicos.ufpe.br/revistas/topicoseducacionais/index 
tipo de educação, no talento ou na capacidade natural da criança. No entanto, para melhor entendimento da perspectiva platônica, é preciso compreender, ainda que rapidamente, o ideal do processo educativo presente na formação do homem grego.

É com base nessa perspectiva que Platão vai propor uma "república de notáveis", ou seja, um processo educativo que tenha como finalidade formar uma aristocracia baseada na capacidade dos cidadãos e não apenas em seu nascimento. Ora, Platão é, de certa forma, fiel aos ideais socráticos. Tanta para um quanto para outro, existe um bem superior que está acima da vontade popular e tal bem é a justiça, sendo que esta pode ser aprendida através do exemplo. Sabe-se que com Sócrates e Platão, houve um deslocamento das discussões em torno da natureza do mundo e de seus elementos primordiais - questões que ocupavam os filósofos pré-socráticos - para questões abstratas e que se relacionavam à definição do que é a virtude, a origem e natureza do conhecimento, a arte do bem viver, as implicações da vida na sociedade e também com os objetivos e finalidades da educação. O que se pode extrair dessas ideias é a noção de "clássico grego" como o grande apanágio que os helênicos se propuseram. De acordo com Osowski (1989, p. 4), essa noção transforma-se em uma espécie de conceito imposto que era a “[...] representação de um mundo melhor, normativo, que deveria, necessariamente, ditar uma forma de vida mais perfeita, mais bela, mais justa a ser seguida por todos", sendo que isso se configurou como a expressão de um idealismo que refletia o pensamento da aristocracia.

Se a educação funciona como um método para a libertação da alma - é o que pode ser retirado do mito da caverna relatado por Platão ${ }^{6}$-, tal libertação deve ser pensada, prioritariamente, para garantir o bom governo da cidade. Assim, uma cidade deve estar apta a selecionar os mais capazes para o exercício da boa administração pública. A esse respeito Platão (409 a.C., p.352 [2019]) destaca que a função dos governantes da polis é fazer com que os bem-dotados a se voltarem tendo em vista o bem-viver comum.

A educação, dessa forma, é a arte de selecionar os mais capazes, treiná-los, a fim de que não voltem "às cavernas"; e colocá-los à prova com a finalidade de terem suas almas habilitadas para o bem comum. A busca é por uma virtude intelectual que se associa a uma ética com caráter inconteste. Trata-se de um método voltado para a "coisa pública", em que a democracia passa a ser

${ }^{6}$ Cf: A República" de Platão. $6^{\circ}$ ed. Ed. Atena, 1956, p. 287-291.

Revista Tópicos Educacionais, Pernambuco, v. 27, n. 01, p. 154-173, 2021. ISSN: 2448-0215. https://periodicos.ufpe.br/revistas/topicoseducacionais/index DOI: 10.51359/2448-0215.2021.250111 
sustentada por uma aristocracia intelectualizada e bem treinada. Em síntese, a educação grega tinha duas finalidades: i) o desenvolvimento do cidadão fiel ao Estado e, ii) a formação do homem que adquiriu plena harmonia e domínio de si. Porém a educação grega também tinha uma finalidade cívica, ou seja, ela era uma preparação para a cidadania. Assim, podemos dizer que, para eles, o habitante da polis só é elevado à categoria de cidadão em função de viver na cidade, dela participar e reconhecer que sem ela ele não é nada.

No ideário platônico, os homens são diferentes por natureza e isso justifica a divisão de classes. A busca, então, na república platônica, era pelos melhores, que deveriam ser os guardiões da cidade, o que incluía seus costumes, suas regras, suas leis. Como se vê, A República é um tipo de discurso fundador ${ }^{7}$ da educação ocidental e já nessa obra ocorre a produção de um discurso sobre o superdotação, um discurso que inscreve o superdotado na instância de um lugar marcadamente valorizado no interesse social de sua época. Um fato interessante a se destacar é a nomeaçãoo que Platão faz de Aristóteles, seu discípulo. Platão, dentre seus alunos, o nomeia como “A inteligência" e o destaca como o melhor de seus alunos. Os relatos dizem que quando Aristóteles faltava às aulas de Platãoo este dizia: "faltou a inteligência" (REALE, 1992). Tal nomeaçãoo, sabemos, não é sem consequências, pois temos em Aristóteles um dos pais da Filosofia e isso, a nosso ver, é um dos efeitos dessa nomeação, o que provoca nele um desejo de saber. se Platão busca um grupo de notáveis para constituir sua república, Aristóteles certamente fazia parte desse grupo, uma vez que sua inteligência era destacável não só pelo mestre Platão mas também por diversos contemporâneos seus (REALE, 1992). Teríamos aí um caso de superdotação como efeito de uma nomeação advinda do "pai do conhecimento"?

Ora, sabemos que as contribuições de Aristóteles para o campo do conhecimento foram grandes e, de longe, ele conseguiu ultrapassar o pai (do conhecimento). Com seus trabalhos, o filósofo grego sistematizou a ciência - e tal sistematização durou por longo tempo -, elaborou uma teoria dos quatro discursos, apresentou as bases da lógica formal, além de diversas contribuições às ciências naturais. Conforme lembra-nos Reale (1992), os escritos de Aristóteles foram variados, indo da Poética, passando pela Retórica, por um livro de Dialética (os Tópicos) e dois tratados de Lógica (Analíticas I e II), além de duas obras introdutórias sobre a linguagem e o pensamento em

\footnotetext{
${ }^{7}$ Um discurso fundador é aquele que inaugura uma discursividade ou uma racionalidade. Refere-se a certos discursos que têm um autor como o instaurador de uma discursividade nova, ou, ainda, que reformula, de modo original, uma discursividade anterior. Assim, Jesus Cristo é um sujeito fundador, pois funda uma nova discursividade, assim como Sócrates também o é, pois funda a Filosofia enquanto campo de saber que se ocupa das questões humanas. Cf: Foucault, 1992.
}

Revista Tópicos Educacionais, Pernambuco, v. 27, n. 01, p. 154-173, 2021. ISSN: 2448-0215.

https://periodicos.ufpe.br/revistas/topicoseducacionais/index 


\section{Revista Tópicos Educacionais}

geral.. Especificamente, ao que se refere à educação, em $A$ Política Aristóteles sustenta que a educação deve preparar o homem para as atividades criadoras da vida ativa na cidade, sendo que, esta é uma forma de comunidade; toda comunidade visa um bem comum e a cidade, enquanto tal, é a maior de todas as comunidades.

Se a nossa finalidade aqui é evidenciar a produção discursiva de um enunciado sobre a superdotação, o discurso platônico ${ }^{8}$ insere-se na ordem de um discurso fundador em torno da educação e, mais especificamente, em torno dos bem dotados, conforme já dito. No entanto, toda uma produção filosófica se formou a partir das concepções iniciais de Platãoo e, tal produção, influenciou o pensar e o agir de educadores e de uma infinidade de teóricos, chegando atéé a contemporaneidade e, como consequência, assumiu um valor de verdade.

De acordo com Michel Foucault (1969), o discurso tido como verdadeiro é portador de poder e a episteme de uma época é portadora de uma verdade enquanto um produto histórico. Da mesma forma que em um determinado momento a loucura foi colocada diante da razão como desrazão, ou como doença mental, na modernidade, a superdotação, é produzida discursivamente. Dessa forma, se na história da educação encontramos um silenciamento em torno da superdotação é porque, a nosso ver, houve também um silenciamento em torno daqueles sujeitos que fracassavam em sua empreitada escolar. Ainda na linha de raciocínio foucaultiano, o silêncio sobre um tema leva a pensar em um outro discurso já-dito "[...] e que este já-dito não seria simplesmente uma frase já pronunciada, um texto já-escrito, mas um 'jamais-dito', um discurso sem corpo, uma voz tão silenciosa quanto um sopro, uma escrita que não é senão o vazio de seu próprio rastro" (FOUCAULT, 1969, p.28).

Assim, após os gregos, não encontramos qualquer manifestação a respeito da superdotação, a não ser alguns poucos sinais na Idade Média, mas, dessa vez, para demonizá-los (VIRGOLIM, 1997). Somente no século XIX é que encontramos uma preocupação em relaçãoo à superdotação, embora Antipoff (1992) sustente a tese de que a Pérsia do século XVI enviava emissários junto aos

\footnotetext{
${ }^{8}$ Aqui destacamos a filosofia grega em função do peso acadêmico que ela possui na formação ocidental. No entanto, é oportuno destacar que o Antigo Testamento relata a preocupação de Nabucodonosor, rei da babilônia, no século V a. C, preocupado em encontrar os mais aptos, os mais sábios e inteligentes para formar um "reino de notáveis" que garantiria o primor do reino da Babilônia. Foi assim que Daniel, o profeta, foi escolhido, ainda jovem, por ter uma inteligência notável, inclusive na arte de interpretar os sonhos do rei. Tal notabilidade garantiu-lhe um lugar no reino, mas que, por seu temor ao Deus de Israel, foi jogado na cova dos leões.
}

Revista Tópicos Educacionais, Pernambuco, v. 27, n. 01, p. 154-173, 2021. ISSN: 2448-0215.

https://periodicos.ufpe.br/revistas/topicoseducacionais/index 
cristãos para descobrir crianças superdotadas que pudessem ser educadas para assumir cargos de comando em sua sociedade ${ }^{9}$.

\section{O início dos estudos na modernidade}

Foram os Estados Unidos da América que retomaram os estudos em torno da superdotação, no século XIX, mesma época em que a escolaridade obrigatória se instaurou, tanto nos Estados Unidos quanto na Europa. Tal momento é importante, pois é um período coincidente com a revolução industrial e com grandes avanços na produção de bens de consumo nos países que começavam a se industrializar. Tal fato, a nosso ver, deve ser pensado a partir de uma lógica discursiva e, mais especificamente, a partir da lógica do capital.

No fim dos anos 1960 Michel Foucault publica $A$ arqueologia do saber, uma obra em que busca afirmar o primado do discurso. O discurso é, a partir de agora, uma prática política na qual há um engajamento de um sujeito e de uma instituição enquanto elementos de uma estrutura. Desse modo, o discurso é concebido como uma dispersão, ou melhor, ele é formado por elementos que não estão ligados por nenhum princípio de unidade, mas que, no entanto, seguem uma determinada regra que, através da dispersão, pode ser acionada e originar as "regras de formação" 10 detectadas por análise do discurso. A regularidade com que a dispersão ocorre pode ser capturada pelas vias do enunciado possibilitando a apreensão do processo, o que leva Foucault (1969, p. 135-6) a designar o discurso como um conjunto de enunciados apoiados em uma mesma formação discursiva, sendo constituído por enunciados dispersos que deverão ser organizados pelo analista.

\footnotetext{
${ }^{9}$ No imaginário católico medieval dos séculos XV e XVI as pessoas que se destacavam por suas façanhas e proezas eram vistas como possuídas ou inspiradas pelos demônios estando, dessa forma, sujeitas à fogueira da inquisição (Cf. VIRGOLIM, 1997).

${ }^{10}$ As regras de formação referem-se a determinadas normas que se apresentam no interior do discurso e que possuem uma regularidade em casa tipologia discursiva. Assim, o discurso político, por exemplo, possui determinadas regras de formação constituída pelo nível dos objetos que o constituem, o nível das formações enunciativas, o nível dos conceitos e o nível das estratégias. Por esses níveis, é possível realizar a identificação de um discurso como sendo político ou não. Para continuarmos em nosso exemplo, o discurso político possui um "jogo de máscaras", em que seus agentes utilizam-se de regras de sedução e persuasão, sempre na perspectiva de que "um outro mundo é possível"; de fato, a promessa é um elemento constitutivo no discurso político.

Revista Tópicos Educacionais, Pernambuco, v. 27, n. 01, p. 154-173, 2021. ISSN: 2448-0215.
}

https://periodicos.ufpe.br/revistas/topicoseducacionais/index 
A localização temporal do discurso remete-nos à materialidade como algo constitutivo do enunciado $^{11}$, não se limitando apenas a esse aspecto, mas estando em relação direta com uma ordem da instituição na qual se torna um acontecimento. Devido a isso, Foucault uma vez mais sustenta que o discurso constitui-se como uma prática que sistematicamente forma o seu objeto. Quando se tenta descrever a dispersão discursiva buscando o estabelecimento de regras de formação dos discursos, se está, no dizer de Foucault (1969), demonstrando as regras de formação que possibilitam listar os elementos constituintes do discurso. Podemos destacar, a partir desse autor, os seguintes elementos: (1) os objetos que aparecem, coexistem e se transformam num "espaço comum" discursivo; 2) os diferentes tipos de enunciação que podem permear o discurso; 3) os conceitos; 4) os temas e teorias, isto é, o sistema de relações entre diversas estratégias capazes de dar conta de uma formação discursiva, permitindo ou excluindo certos temas ou teorias.

Finalmente, encontramos no filósofo francês o conceito de Formação Discursiva ${ }^{12}$ cujos elementos que lhes são constitutivos são governados por um sistema de regras de formação, determinadas historicamente. Tais regras fundam a unidade de um conjunto de enunciados sócio historicamente circunscrito, que possibilita a dizer quem fala e de onde esse sujeito fala. Em decorrência disso, o discurso é concebido como um jogo ao mesmo tempo estratégico e polêmico, sendo, portanto um local de embate, de conflito por ser um espaço onde saber e poder se articulam. Desta forma, todo discurso repousa sobre um já-dito, conforme já apontamos anteriormente. Com isso, Foucault (1969, p. 32) faz a suposição de que todo discurso já se encontra articulado no "meio-silêncio" prévio, “[...] que continua a correr obstinadamente sob ele, mas que ele recobre e faz calar".

A superdotação, enquanto tema de estudo, aparece nos Estados Unidos no século XIX, é de alguma forma marcado pela concepção de hereditariedade. Neste aspecto, o trabalho do sociólogo francês Moreau de Tours, um tipo de "expert" em patologia mental, teve uma forte influência. Virgolim (1997, p. 176) destaca que, para Moreau “[...] o gênio seria o resultado de um desvio mórbido de um tipo original, de uma árvore genealógica neuropática", o que conformaria um tipo de "doente mental". De fato, a tônica do século XIX é a questão da hereditariedade e, em 1869,

\footnotetext{
${ }^{11}$ Tanto em Foucault (1971) quanto em Bakhtin (1992), um enunciado é sempre um acontecimento. Ele demanda uma situação histórica definida, atores sociais plenamente identificados, o compartilhamento de uma mesma cultura e o estabelecimento necessário de um diálogo; acontece em um determinado local e em um tempo determinado, é produzido por um sujeito histórico e recebido por outro. Refere-se à materialidade do discurso.

12 “A formação discursiva se define como aquilo que numa formação ideológica dada- ou seja, a partir de uma posição dada em uma conjuntura sócio- histórica dada- determina o que pode e o que deve ser dito." (ORLANDI, 1992).

Revista Tópicos Educacionais, Pernambuco, v. 27, n. 01, p. 154-173, 2021. ISSN: 2448-0215.

https://periodicos.ufpe.br/revistas/topicoseducacionais/index
} 
Francis Galton (1869) publicou Hereditary Genius, obra na qual procurou demonstrar que havia uma semelhança entre a transmissão de traços físicos e mentais. Para ele, as habilidades mentais possuíam um importante e decisivo aspecto de hereditariedade. Discursivamente, Galton insere-se em uma tradição evolucionista, a mesma de seu primo Darwin (1859), em que há uma continuidade física e psicológica entre as espécies e, assim como nos animais, os indivíduos mais inteligentes podem ser caracterizados por capacidades sensoriais mais finas e apuradas (GALTON, 1869; BRANCO, 2004). Por esse caminho, torna-se mais do que evidente que este modo de apreensão da superdotação passa pela noção de genialidade e esta, necessariamente, liga-se aos aspectos hereditários. E como se trata de um trabalho essencialmente darwinista, a concepção de inteligência e superdotação de Galton passa necessariamente pelo processo de seleção natural e adaptação $^{13}$. Assim, ser bem dotado ou superdotado relaciona-se a um dote, a um dom que o sujeito recebe e, por isso mesmo, fornece uma série de indicativos sobre o plano excessivo da atividade cognitiva que não deixará de ser agrupada ao conceito de superdotação.

Ora, se o fracasso escolar é uma patologia relativamente recente, conforme faz-nos crer Cordié (1996), a superdotação não o é, não sendo, também, considerada uma patologia, apesar de algumas indicações encontradas no campo da psiquiatria ${ }^{14}$. Pelo contrário, a superdotação é vista como um plus, um "a mais" que o sujeito porta e o faz destacar-se ante aos demais. É um pouco nessa perspectiva que o trabalho de Alfred Binet, em 1905, inscreve-se. Com a criação de um método de aferição da inteligência, o teste cunhado por esse psicólogo francês permitiu apontar crianças superdotadas, ou seja, aquelas que apresentavam um quociente de inteligência (Q.I) igual ou superior a 140 pontos. Segundo Binet e Simon (1929, p. 26), o teste criado por eles foi pensando a partir da ideia de se determinar "[...] crianças cuja fraqueza de intelligencia exija matrícula em classes especiaes ou em internatos". No entanto, destacam aqueles cuja inteligência os colocaria em "classes de Elites". É neste momento que uma nascente ciência psicológica apropria-se dos estudos da inteligência e passa a definir quem são os superdotados, os medianamente dotados ou os infradotados. Nesta perspectiva, podemos dizer que Alfred Binet "inventou” a inteligência ao garantir uma consistência científica a um tema que até então era

\footnotetext{
${ }^{13}$ Não entraremos nas discussões em torno dos efeitos desse tipo de pensamento na história da educação. Entretanto, gostaríamos de destacar que a doutrina de Galton teve forte influência no conceito de inteligência com suas respectivas consequências para a realidade escolar. Parece-nos, assim, que a seleção natural traduziu-se em seleção social e garantiu méritos aos que melhor se adaptam à realidade escolar com suas rotinas.

${ }^{14}$ É oportuno destacar, aqui, o modo como os manuais de psiquiatria infantil tratam a superdotação. Em alguns manuais (Ajuriaguerra, 1983; Marcelli, 1998), a superdotação aparece como um desajuste ou inadequação no campo escolar.
}

Revista Tópicos Educacionais, Pernambuco, v. 27, n. 01, p. 154-173, 2021. ISSN: 2448-0215.

https://periodicos.ufpe.br/revistas/topicoseducacionais/index 
tomado como um capítulo dos tratados de filosofia ou mesmo como algo ligado aos aspectos sensórios-motores simples, como era o caso de Galton.

Ora, Foucault (1975) sustenta que a psicologia é a disciplina da norma, a começar pelo fato dela aparecer aliada aos imperativos epistemológicos positivistas e, ainda, ao estabelecimento de uma "sociabilidade normal". O que encontramos nos testes de Binet é exatamente uma padronização em torno de uma inteligência dita normal, cuja finalidade era, principalmente, indicar os inaptos a seguir uma escola regular e encaminhá-los aos serviços de treinamento presentes na educação especial da época. Trata-se, para Foucault (1975), de uma operação discursiva. Conforme já vimos, o discurso, em Foucault, é visto como uma relação entre enunciados. Para esse autor, o discurso é uma relação entre enunciados que se articulam, de modo disperso. Desse modo, há enunciados sobre a loucura, sobre a desordem, sobre a incapacidade e também sobre a superdotação. Os sobre a superdotação, não só falam sobre ela, mas, também, respeitam modalidades particulares de sua formação. $\mathrm{O}$ que podemos extrair disso é que os enunciados sobre a inteligência e, de modo mais específico sobre a superdotação, embora aconteçam de forma relativamente contínua, suas regras de formação modificam-se no decorrer do tempo, sendo, portanto, descontínuas. Assim, encontramos um enunciado a respeito da superdotação que associa os mais aptos ao governo de uma nação democrática, como é o caso da Grécia antiga; há também enunciados sobre os bem dotados que os associa a poderes sobrenaturais, como é o caso das sociedades árabes medievais; encontramos ainda enunciados sobre a inteligência que agregam tal conceito ao lucro, como acontece, de certo modo, na contemporaneidade. Em síntese, a tese de Foucault é de que só é possível definir uma dada formação discursiva a partir de um determinado momento histórico, uma vez que há um espaço de ordem que o possibilita. Desse modo, uma análise de um determinado discurso deve ser feita com base nos elementos que possibilitam, em determinada época, aparecer certos saberes e práticas.

Ora, sabemos que a universalização da educação na Europa e nos Estados Unidos aconteceu, de certa maneira, para atender aos interesses e às necessidades de mão de obra que a revolução industrial dos séculos XVIII e XIX passou a requerer ${ }^{15}$. Formar mais cidadãos, mais bem treinados e educados atenderia muito bem aos interesses de um capitalismo ainda nascente. Assim, definir através de uma psicometria aqueles que eram mais ou menos aptos ao estudo e a determinado tipo de trabalho era também o interesse de um mercado cada vez mais demandante e exigente. Se os

\footnotetext{
${ }^{15}$ Cf: HOBSBAWM, Eric J. A Era das Revoluções - Europa 1789-1848. Rio de Janeiro: Paz e Terra, 1989. Revista Tópicos Educacionais, Pernambuco, v. 27, n. 01, p. 154-173, 2021. ISSN: 2448-0215. https://periodicos.ufpe.br/revistas/topicoseducacionais/index DOI: 10.51359/2448-0215.2021.250111 
testes pudessem dizer quem era incapaz de seguir uma escola normal, melhor seria se eles pudessem identificar aqueles que eram mais capazes que os outros. Desse modo, o teste de inteligência se configura como importante acontecimento discursivo no que diz respeito ao conjunto de enunciados sobre a superdotação. Conforme dito, o teste criado por Binet e Simon não teve como objetivo verificar os mais capazes; muito antes, pelo contrário, sua finalidade foi verificar aqueles que não estavam aptos a seguir o curso de uma escola normal, a partir da realização de um exame psicológico, associado ao exame médico e ao pedagógico. Foram os estudos de Terman (1919) que apontaram para a possibilidade do uso do teste de Binet para selecionar os superdotados. Dessa forma, temos, em Terman, o nascimento da superdotação na modernidade como efeito do discurso da ciência.

A nosso ver, a revolução industrial dos séculos XVIII e XIX pode ser vista como uma superfície primeira da emergência do discurso a respeito da superdotação em função do valor de mercado que a inteligência passa a ocupar no século XX. Dessa maneira, o ato empreendido por Alfred Binet e Theodore Simon insere-se como fato fundamental na emergência do discurso psicológico, pois prescreve uma "instância de delimitação" (FOUCALT, 2010 [1969], p. 47) da psicologia. A psicologia agora ultrapassa aos laboratórios de fisiologia que se ocupavam em observar e descrever o comportamento animal, e passa a ser um campo da ciência que possui, através da avaliação da inteligência, uma função social ampla e começa, desse modo, a ser aquele campo do saber que, enquanto instituição, possui a técnica da testagem; é formada por um conjunto de indivíduos que constituem seus avaliadores; constrói um saber e uma prática sobre a inteligência; detém uma competência reconhecida pelos órgãos de Estado e pela opinião pública. É assim que ela se torna, no século XIX, a instância superior que, na sociedade e na academia, nomeia, estabelece, cria e designa o objeto inteligência.

Em seu constructo teórico, Foucault (1969) alerta-nos para a dimensão imaginária do poder, sustentando que há várias de suas representações. Para esse autor, a dominação é muito mais sofisticada e complexa do que se apresenta. Assim, ele questiona a noção de poder como repressão, tão cara ao marxismo e chama a atenção para seus efeitos sobre o corpo do indivíduo, enquanto biopoder. Com tal noção, o questionamento incide ainda sobre o conceito corrente de ideologia, uma vez que não apenas o mental do indivíduo encontra-se afetado pelo poder, mas sim o seu corpo, seus gestos, suas posturas, seu comportamento, enfim, toda sua corporalidade. De modo mais específico, os estudos do filósofo francês destacam que, na contemporaneidade, a ciência ocupa um lugar privilegiado enquanto instância de poder. Poder e saber caminham em uma Revista Tópicos Educacionais, Pernambuco, v. 27, n. 01, p. 154-173, 2021. ISSN: 2448-0215. https://periodicos.ufpe.br/revistas/topicoseducacionais/index DOI: $10.51359 / 2448-0215.2021 .250111$ 


\section{Revista Tópicos Educacionais}

relação estreita e direta e, em Foucault (1969; p. 30), o poder produz saber, não havendo relação de poder sem uma ressonância correlata no campo do saber. Do mesmo modo, não existe um saber que não se constitua em relações de poder tendo em vista que o poder produz saber e se encontram diretamente implicados.

Em uma época em que o imperativo da produção e do desempenho inscrevem-se como fatores preponderantes, a superdotação reaparece como algo que atende muito bem a uma função de ideal, principalmente quando ancorado no discurso da ciência. É evidente para nós, no entanto, que não se trata de uma obviedade do discurso, a começar pela conotação que damos às considerações de Foucault. O discurso, conforme temos argumentado, é concebido como uma dispersão, como um conjunto de enunciados que remetem a uma mesma formação discursiva, com seus princípios de regularidade. Assim, dizer de uma dada formação discursiva, analisá-la, é descrever os enunciados que a compõem. Desse modo, queremos pensar, de modo mais preciso, o significado que se dá ao termo superdotação e, por conseguinte, à força que se concede ao discurso da ciência na vida atual.

Superdotação, opondo-se ao fracasso, implica na emissão de um juízo de valor que, por sua vez, é função de um ideal, conforme permite-nos discutir Cordié (1996). Para essa autora, com quem concordamos neste aspecto, o sucesso, na sociedade ocidental, se traduz através do verbo "ter": ter acesso ao consumo de bens, ter boa posição social, em resumo, o que para psicanálise pode-se pensar como: ter o falo imaginário. A concepção de falo imaginário está ligada à ideia de uma completude, de algo que torna pleno o ser que o possui. Em "os três tempos do complexo de Édipo" (1957- 1958), Lacan vai dizer que o primeiro tempo, é o tempo da demanda, sendo caracterizado pela relação dual, imaginária, entre a criança e a mãe, em que a criança tem a ilusão de complementaridade com o corpo da mãe. Da mesma forma, a criança se identifica de forma especular com o falo imaginário, pois este é o objeto de desejo materno. Assim, ela é o falo que falta à mãe. A partir da perspectiva lacaniana, pode-se dizer que o falo imaginário é "significante da Falta do Outro" e a ilusão de se tê-lo é a ilusão de completude.

Ao fracasso, talvez poderíamos pressupor o oposto a tudo isso, o que implica na não realização do "ter", uma vez que, em tese, o sujeito estaria privado de usufruir daquilo que a sociedade dispõe aos que podem adquirir. Para a psicanalista francesa:

Ser bem-sucedido na escola é ter a perspectiva do ter, mais tarde, uma bela situação, de ter acesso, portanto, ao consumo de bens. Significa também "ser alguém", isto é, possuir o falo imaginário, ser considerado, respeitado. O dinheiro e o poder, não eles a felicidade? $\mathrm{O}$ 
próprio Estado alimenta essa aspiração. Para ser grande uma nação não deve sempre aumentar suas riquezas e suas competências? O fracasso escolar pressupõe a renúncia a tudo isso, a renúncia ao gozo. (CORDIÉ, 1996, p.21)

A partir do enunciado acima, podemos interrogar se a superdotação seria o oposto a tudo isso, pois uma vez que Ter uma inteligência brilhante representaria a posse do falo imaginário e, por conseguinte, seria a garantia de sucesso para os superdotados. Conforme orienta Lacan (1957), de início, a criança se coloca como algo dirigido a seus pais e, mais ainda, constitui-se como elemento essencial da relação da criança com o Outro, o que constitui para ela o que Freud já denominava de mãee.

\section{3. $O$ século XX e os primeiros passos na cientifização da Inteligência}

Qualquer alusão que se faça à superdotação na contemporaneidade a ideia de inteligência privilegiada é o elemento mais evidente. De certo modo, o imaginário tratou de contribuir para a construção das teorias que tratam da superdotação no início do século XX e fizeram com que a inteligência se tornasse um dos elementos mais desejados do ponto de vista cognitivo ${ }^{16}$. No que diz respeito à superdotação, de modo mais específico, a noção de genialidade foi amplamente utilizada para caracterizar tais sujeitos. De acordo com Alencar (2007), Terman, a título de exemplo, nos anos 1920, realizou um estudo longitudinal com 1500 crianças identificadas como superdotadas em testes de inteligência, na expectativa de que se tornassem gênios.

No entanto, os testes que foram amplamente utilizados no século XX para identificar o superdotado, foram usados, inicialmente, para a detecção de crianças ditas anormais. O teste elaborado por Binet é proveniente de uma demanda do governo francês em avaliar crianças que possuíam dificuldades em acompanhar o processo escolar. Com a universalização do ensino e a frequência obrigatória das crianças em escolas públicas francesas, a partir de 1881, a categoria dos “incapazes" aparece no discurso da escola. Incapazes são aqueles que não conseguem seguir as instruções em uma sala de aula regular. É a partir dessa percepção que o Ministério da Educação Francês convoca Binet para presidir uma comissão que pudesse avaliar e identificar tais crianças

\footnotetext{
${ }^{16}$ Em enquete realizada em 1986, Alencar verificou que a alta inteligência é um dos atributos mais desejáveis entre crianças matriculadas nas $3^{\mathrm{a}}$ e $4^{\mathrm{a}}$ séries do Ensino Fundamental, além de ser, no imaginário dessas crianças, a característica mais desejável por parte dos professores. Em uma pesquisa semelhante realizada no decorrer deste doutorado, chegamos a uma constatação parecida.
}

Revista Tópicos Educacionais, Pernambuco, v. 27, n. 01, p. 154-173, 2021. ISSN: 2448-0215.

https://periodicos.ufpe.br/revistas/topicoseducacionais/index 
para, em seguida, encaminhá-las para a educação especial. O teste elaborado por ele e seus colaboradores consiste em uma série de exercícios projetados para medir "os processos mentais superiores" (BINET, 1928, p. 12), tais como memória, imaginação, atenção, sentimentos morais, dentre outros. Assim, Binet estabelece uma norma empírica capaz de categorizar a inteligência. Neste exame, os pesquisadores liderados por esse advogado francês elaboraram uma escala cujos trinta itens foram organizados em ordem crescente de dificuldade, padronizados para crianças de três a onze anos de idade e aplicados em alunos das escolas parisienses. Binet, inspirado pelos métodos provenientes das ciências naturais, os associou aos métodos das ciências exatas, cuja finalidade era garantir à sua pesquisa o estatuto de ciência. Em seu método, verifica-se que o pesquisador francês incorporou dois importantes aportes teóricos do século XIX, que foram o evolucionismo darwiniano e a fisiologia humana. É com base nesses dois aspectos que a psicologia diferencial se fundamenta e, de acordo com Patto (1999), esse ramo psicológico se apropria dos conceitos de "variação", "seleção" e "adaptação" da teoria evolucionista, empregando-os no estudo das capacidades mentais individuais. Também toma algumas contribuições da fisiologia, como os resultados das pesquisas laboratoriais sobre a correlação entre discriminação sensorial e processos fisiológicos e psicológicos. Para ela, a fisiologia da época estava submergida pelo darwinismo, com suas noções de degenerescência, atraso mental, resistência psicofísica e se relacionavam à concepção de inabilidade de ajustamento na batalha pela vida.

Segundo Santiago, o teste de Binet e Simon "torna-se o ponto de partida central em torno do qual se elabora uma série de outros testes psicológicos mais específicos destinados a discernir e mensurar, separadamente, cada uma das atividades cognitivas...” (SANTIAGO, 2005, p. 62). Assim, os testes que passaram a ser elaborados no século XX são, de algum modo, tributários aos trabalhos elaborados por esses professores franceses. De acordo com aquilo que já foi apontado anteriormente, a perspectiva inicial de Binet era a de identificar os incapazes à escolarização e tratava-se de um teste que englobava três campos de avaliação, a saber: i) médica, cuja finalidade era verificar os sinais anatômicos e fisiológicos da inferioridade intelectual; ii) pedagógica, cujo objetivo era o de avaliar a inteligência com base em uma dimensão conceitual adquirida e, por fim, iii) psicológica, que tinha a meta de realizar observações diretas e medições do grau de inteligência, a partir da capacidade intelectual da criança.

Em síntese, pode-se dizer que o discurso de Alfred Binet sobre a inteligência centra-se na capacidade que as pessoas têm em abordar e resolver problemas. No entanto, a constatação da Revista Tópicos Educacionais, Pernambuco, v. 27, n. 01, p. 154-173, 2021. ISSN: 2448-0215. https://periodicos.ufpe.br/revistas/topicoseducacionais/index DOI: $10.51359 / 2448-0215.2021 .250111$ 
inteligência só se dá, nessa perspectiva, a partir da elaboração de um método quantitativo capaz de classificar os indivíduos com base em sua idade mental, medida por seu teste.

No entanto, a proposta de se medir a inteligência usando o QI é feita por William Stern, psicólogo alemão que propôs a conhecida razão entre Idade Mental/ Idade Cronológica (BRANCO 2004). Desse modo, se Binet "cria", do ponto de vista discursivo, a inteligência, Stern "cria", desse mesmo ponto de vista, o QI, que esfumaça o nome daquele que deu os primeiros passos na medida científica da inteligência e, ao fazer isso, estabelece uma concepção em torno da formação discursiva que passa a prevalecer na noção de inteligência com seus sucedâneos, tais como a educação e a seleção profissional.

\section{Considerações finais: uma visada no contemporâneo}

Segundo Lipovetsky (2007, p. 11), um traço importante na sociedade contemporânea é o que criou uma "[...] religião do melhoramento contínuo das condições de vida, o maior bem-estar tornou-se uma paixão de massa, o objetivo supremo das sociedades democráticas, um ideal exaltado em todas as esquinas". É neste sentido que se pode dizer que a lógica principal a reger o consumo é aquela que se encontra diretamente ligada às "experiências emocionais" e a uma elevação da felicidade enquanto um valor cultural. Ora, se a felicidade é um valor cultural, os ideais, de certo modo, existem para garantir que aquele que a eles se associam, recebam uma cota mínima desse valor.

Como uma certa consequência da mutação dos ideais e o estado de paixão de massa que o bem-estar passou a ocupar na contemporaneidade, a mudança na forma de consumo sofreu alterações significativas, pois o consumidor antigo encontra-se agora no status de hiperconsumidor, sempre "[...] à espreita de experiências emocionais e de maior bem-estar, de qualidade de vida e de saúde, de marcas de autenticidade, de imediatismo e de comunicação. O consumo idealizado tomou o lugar do consumo honorífico..." (LIPOVETSKY, 2007, p. 14). Este hiperconsumidor não se encontra nesta categoria apenas em função da quantidade que ele consome; sua posição deve-se também ao fato de sua forma de consumo centrar-se em um consumo emocional do tipo individualista, que tem sua marca em uma busca por uma felicidade privada.

Na perspectiva adotada por Lipovetsky, o hiperconsumo refere-se à nova fase que o mercado 
assumiu a partir dos anos 1970. Esta nova fase significa a relação emocional que as pessoas têm com as mercadorias, representada por certa paixão pelas marcas e a felicidade que isso possa acarretar. Assim, a fase III $^{17}$, como é denominada a fase do hiperconsumo, tem como marca a busca pela satisfação emocional imediata e infiltra-se nas relações do consumidor com a família, com a religião, com a escola, com a política, com o lazer e com todas as facetas que a vida dele possa assumir.

No entanto, com o imperativo categórico que o hiperconsumo assumiu e sua direta associação com a felicidade, o consumo emocional, supostamente acarretador desta felicidade, apresenta seus paradoxos: discurso da felicidade e aumento da depressão; aumento da liberalidade dos costumes e expansão do sofrimento psíquico em crianças e adolescentes. Nesse sentido a leitura desse autor sobre a condição atual aponta para o fato de que mesmo que a maioria se diga feliz, a tristeza, o estresse, a depressão, dentre diversas outras formas de sofrimento mental aumentam vertiginosamente. De fato, trata-se de um imperativo da felicidade. Associado a este imperativo, um outro se faz presente na contemporaneidade que é aquele da busca pelo aumento do desempenho e o ideal de superação, seja em qual esfera for. No caso que nos interessa aqui, enfatizamos o hiperdesempenho buscado na vida acadêmica e que tem como referência mais evidente a inteligência. É de conhecimento geral que a inteligência encontra-se, no Ocidente, como um atributo muito desejado. Trata-se, dessa forma, de um ideal altamente valorizado na cultura ocidental. Sabemos que na complexificação da escolarização a que chegamos, possivelmente não haja outro atributo mais valorizado que a inteligência. Tal valorizaçãoo é facilmente perceptível por qualquer pessoa quando nos referimos a certa idealização em torno da escola, da criança, do adolescente e das possibilidades de trabalho que o país oferece. Há um status elevado da inteligência na vida social e, como não poderia deixar de ser, reproduzido pela escola.

Da mesma maneira, com a valorização da inteligência pelo discurso social, encontramos a ciência, principalmente sustentada pela psicologia e pela neurociência, ocupando-se em desvendar os "mistérios" da inteligência bem como de seu fracasso. De modo geral, permanece uma instância avaliadora proveniente do discurso do Outro que faz com que haja uma nomeação em torno das

\footnotetext{
${ }^{17}$ Para Lipovetsky (2007), o capitalismo de consumo viveu três eras: i) a era I, denominada de era do consumo de massa, que surgiu nos anos de 1880 e durou até o final da segunda guerra mundial; ii) a era II foi denominada de sociedade da abundância, que foi de 1950 até final dos anos de 1970. Tal fase encontra-se em declínio desde a década de 1970 e coincide também com o modelo puro da "sociedade de consumo de massa"; iii) a era III é a que discutimos brevemente no corpo do texto.
}

Revista Tópicos Educacionais, Pernambuco, v. 27, n. 01, p. 154-173, 2021. ISSN: 2448-0215.

https://periodicos.ufpe.br/revistas/topicoseducacionais/index 
crianças e adolescentes e que seja tida como algo finalista: ou se é ou não se é inteligente. Na contemporaneidade, nos diz Viganó (2005, p. 17), a avaliação nos permite passar “[...] da ordem da ciência ao empirismo da perícia, constituindo um parecer que utiliza a competência científica. Recolhem-se os dados e, com a dificuldade de agregá-los, surgem as hipóteses e as teorias". A questão maior que surge como decorrência disso, a nosso ver, é o caráter criacionista do significante, ao nomear os sujeitos - e por vezes, segregá-los - como infradotados, medianamente dotados ou superdotados.

Entretanto, ao que nos parece, a superdotação não é uma questão da contemporaneidade. Do que podemos inferir, se refere a um fato socialmente circunscrito em uma dada época e que chegou atéé nossos dias. Trata-se, conforme tentaremos demonstrar, de uma produção discursiva construída no decorrer da história da educação. Desse modo, no presente capítulo, pretendemos apresentar, a partir de uma interface da psicanálise com a educação, o modo como o conceito foi construído no decorrer do tempo, bem como os pressupostos que sustentam tal construção. Assim, buscaremos retomar os conceitos historicamente elaborados para verificarmos suas vicissitudes na contemporaneidade.

\section{REFERÊNCIAS}

ALENCAR, Eunice Soriano de. Características sócio emocionais do superdotado: questões atuais. In: Psicologia em Estudo. Maringá, v. 12, n. 2, p. 371-378, maio/ago. 2007.

ANTIPOFF, H. (1992). Educação dos Excepcionais. Em coletânea de Obras Escritas de Helena Antipoff - Educação do Excepcional (pp.149-150). Belo Horizonte: Centro de Documentação e Pesquisa Helena Antipoff.

ARISTÓTELES (330 a.C). A política. Brasília: Editora da UNB, 1985.

BAUMAN, Z. Globalização: as consequências humanas. Rio de Janeiro: Jorge Zahar, 1999.

BINET, Alfred; SIMON, Theodore. La medida del desarrollo de la inteligencia en los niños. Madrid Hernando, 1928.

BINET, Alfred; SIMON, Theodore. Testes para a medida de desenvolvimento da intelligência nas crianças. São Paulo: Melhoramentos, 1929.

BRANCO, Alexandra. Para além do QI. Lisboa: Quarteto, 2004.

COHEN, R. H. P. A lógica do fracasso escolar: psicanálise e educação. Rio de Janeiro: Contra Capa, 2006.

Revista Tópicos Educacionais, Pernambuco, v. 27, n. 01, p. 154-173, 2021. ISSN: 2448-0215.

https://periodicos.ufpe.br/revistas/topicoseducacionais/index 
$1-$

CORDIÉ, A. Os Atrasados não Existem: Psicanálise de Criança com Fracasso Escolar. Porto Alegre: Artes Médicas, 1996.

FOUCAULT, M. A arqueologia do saber. Rio de Janeiro: Forense Universitária, 1969.

FOUCAULT, Michel. A ordem do discurso: aula inaugural do Collége de France. São Paulo: Loyola, 1975.

GALTON, Francis. Hereditary Genius: An Inquiry Into Its Laws And Consequences. London Macmillan And Co., 1896.

GIDDENS, Anthony. O mundo na era da globalização. Lisboa: Presença, 2000.

GILES, Thomas Ranson. História da Educação. São Paulo: EPU, 1987.

JAMESON, F. Pós-modernismo e sociedade de consumo. Em: JAMESON, F. A virada cultural: reflexões sobre o pós-moderno. Rio de Janeiro: Civilização Brasileira, 2006.

LACAN, J. (1957- 1958). O seminário, livro 5: As formações do inconsciente. Rio de Janeiro: Zahar, 1999. p.166- 184.

LACAN, J. (1969- 1970) O seminário, livro XVII: O avesso da psicanalise. Rio de Janeiro, Zahar, 1992.

LACAN, J. (1969) Notas sobre a criança. In: LACAN, J. Outros escritos. Rio de Janeiro: Zahar, 2003. p.369- 370.

LIPOVETSKY, Gilles. A felicidade paradoxal: ensaio sobre a sociedade de hiperconsumo. São Paulo: Companhia das Letras, 2007.

MILLER, Jacques-Alain, El Otro que no existe y sus comités de ética. Buenos Aires: Paidós, 2006.

OSOWSKI, C. I. Os chamados superdotados: a produção de uma categoria social na sociedade capitalista. Tese (Doutorado) Ciências Humanas e Educação, Universidade Federal do Rio Grande do Sul. 1989, 248 fls. Porto Alegre: UFRGS, 1989.

PATTO, Maria Helena S. A produção do fracasso escolar: histórias de submissão e rebeldia. São Paulo: Casa do Psicólogo, 1999.

PLATÃO (409 a. C). A república. Lisboa: Fundação Calouste Gulbenkian, 1972.

POPPER, K. (1966): Les Fondements Philosophiques des Systemes Economiques, Paris: Ed. Emil M. Classen, Payot, p. 148-150.

REALE, Giovanni. História da filosofia antiga, II: Platão e Aristóteles. São Paulo: Loyola, 1992. $1^{\text {a }}$ edição em italiano: 1975.

Revista Tópicos Educacionais, Pernambuco, v. 27, n. 01, p. 154-173, 2021. ISSN: 2448-0215.

https://periodicos.ufpe.br/revistas/topicoseducacionais/index 
REALE, Miguel. Introdução à filosofia / Miguel Reale. São Paulo : Saraiva, 1992.

SANTIAGO, Ana Lydia Bezerra. A inibição intelectual na psicanálise. Rio de Janeiro: Zahar, 2005.

SANTOS, Milton. Por uma outra globalização: do pensamento único à consciência universal. São Paulo : Record, 2000.

TERMAN, L. M. Genetic studies of genius: Vol. 1. Mental and physical traits of a thousand gifted children. California: Stanford University Press, 1926.

TERMAN, L. The measurement of intelligence: an explanation of and a complete guide for the use of the Stanford revision and extension of the Binet Simon intelligence scale. Cambridge: Riverside press, 1916.

TERMAN, Lewis. M. The Intelligence of School Children: How Children Differ in Ability, the use of Mental Tests in School Grading and the Proper Education of Exceptional Children. Boston: Houghton Mifflin \& Company, 1919.

VIRGOLIM, A.M.R. O indivíduo superdotado: história, concepção e identificação. Psicologia Teoria e Pesquisa, v.13, p.173-183, 1997. 